\title{
Forced abstinence from cocaine self-administration is associated with DNA methylation changes in myelin genes in the corpus callosum: a preliminary study
}

\author{
David A. Nielsen ${ }^{1}{ }^{*}$, Wen Huang ${ }^{1}$, Sara C. Hamon ${ }^{2}$, Lorena Maili ${ }^{3}$, Brian M. Witkin ${ }^{4}$, Robert G. Fox ${ }^{4}$, \\ Kathryn A. Cunningham ${ }^{4}$ and F. Gerard Moeller ${ }^{3}$
}

\author{
Menninger Department of Psychiatry and Behavioral Sciences, Baylor College of Medicine, and the Michael E. DeBakey Veterans Administration Medical Center, \\ Houston, TX, USA \\ ${ }^{2}$ The Rockefeller University, New York, NY, USA \\ ${ }^{3}$ Center for Neurobehavioral Research on Addictions, Department of Psychiatry and Behavioral Sciences, University of Texas Health Science Center Houston, \\ Houston, TX, USA \\ ${ }^{4}$ Center for Addiction Research, Department of Pharmacology and Toxicology, University of Texas Medical Branch, Galveston, TX, USA
}

\section{Edited by:}

Thomas Kosten, Baylor College of Medicine, USA

\section{Reviewed by:}

Thomas Kosten, Baylor College of Medicine, USA

Thomas Newton, Baylor College of Medicine, USA

*Correspondence:

David A. Nielsen, Menninger Department of Psychiatry and Behavioral Sciences, Baylor College of Medicine, and the Michael E. DeBakey Veterans Administration Medical Center, 2002 Holcombe Blvd, Research 151, Building 110, Suite 227, Houston, TX 77030, USA. e-mail:nielsen@bcm.edu
Background: Human cocaine abuse is associated with alterations in white matter integrity revealed upon brain imaging, an observation that is recapitulated in an animal model of continuous cocaine exposure. The mechanism through which cocaine may affect white matter is unknown and the present study tested the hypothesis that cocaine self-administration results in changes in DNA methylation that could result in altered expression of several myelin genes that could contribute to the effects of cocaine on white matter integrity. Methods: In the present study, we examined the impact of forced abstinence from cocaine self-administration on chromatin associated changes in white matter. To this end, rats were trained to self-administer cocaine $(0.75 \mathrm{mg} / \mathrm{kg} / 0.1 \mathrm{~mL}$ infusion) for 14 days followed by forced abstinence for 1 day $(n=6)$ or 30 days $(n=6)$ before sacrifice. Drug-free, sham surgery controls $(n=7)$ were paired with the experimental groups. Global DNA methylation and DNA methylation at specific CpG sites in the promoter regions of myelin basic protein (Mbp), proteolipid protein-1 (P/p1), and SRY-related HMG-box-10 (Sox10) genes were analyzed in DNA extracted from corpus callosum. Results: Significant differences in the overall methylation patterns of the Sox 10 promoter region were observed in the corpus callosum of rats at 30 days of forced abstinence from cocaine self-administration relative to sham controls; the $-189,-142,-93$, and -62 CpG sites were significantly hypomethylated point-wise at this time point. After correction for multiple comparisons, no differences in global methylation or the methylation patterns of Mbp or Plp1 were found. Conclusion: Forced abstinence from cocaine self-administration was associated with differences in DNA methylation at specific $\mathrm{CpG}$ sites in the promoter region of the Sox 10 gene in corpus callosum. These changes may be related to reductions in normal age related changes in DNA methylation and could be a factor in white matter alterations seen after withdrawal from repeated cocaine self-administration. Further research is warranted examining the effects of cocaine on DNA methylation in white matter.

Keywords: cocaine, corpus callosum, gene, self-administration, white matter, epigenetics

\section{INTRODUCTION}

There is a growing body of evidence from human imaging studies that chronic cocaine users exhibit altered white matter (Lim et al., 2002, 2008; Moeller et al., 2005; Ma et al., 2009; Lane et al., 2010). Diffusion tensor imaging (DTI) studies have shown reduced fractional anisotropy (FA), which suggests altered white matter integrity in the corpus callosum (Moeller et al., 2005; Ma et al., 2009) and frontal white matter tracts (Lim et al., 2002) in cocaine dependent subjects compared to non-cocaine using controls. These differences in white matter integrity appear to have functional significance, as they are related to behavioral measures of impulsivity and decision making (Lim et al., 2008; Lane et al.,
2010), as well as treatment outcome (Xu et al., 2010a). Further support for an association between white matter changes and cocaine abuse is provided by a post-mortem study showing that cocaine abusers had reduced expression of the transcript encoding proteolipid protein-1 (PLP1) compared to matched control subjects (Kristiansen et al., 2009).

A question that remains from these studies is whether cocaine is causal in the association between white matter impairment and cocaine abuse. A recent DTI study demonstrated that continuous exposure to cocaine administered via osmotic mini pumps resulted in significantly lower FA in the corpus callosum compared to rats administered saline (Narayana et al., 2009). In addition, 
significantly lower myelin basic protein (MBP) in the corpus callosum of rats was confirmed histologically after continuous cocaine exposure relative to controls (Narayana et al., 2009). This study supports cocaine as a potential causal agent in the white matter changes seen in cocaine abusers. However, the precise mechanisms of action by which cocaine to alters white matter remain unknown.

Myelin is an essential component of white matter (Nave, 2010). Several proteins have been shown to be important for myelin production, including PLP1, MBP, and the transcription factor SRY-related HMG-box-10 (SOX10). PLP1 and MBP are the predominant proteins of the myelin sheath produced by oligodendrocytes (Harauz et al., 2009). SOX10 is an essential transcription factor regulating oligodendrocyte differentiation. Mice deficient in Sox10 develop precursor oligodendrocytes, but differentiation to mature oligodentrocytes is disrupted (Stolt et al., 2002), and recent studies have shown that SOX10 is required for the survival of myelinating oligodendrocytes (Takada et al., 2010). There is evidence that the production of these proteins is affected by chromatin associated changes since an age related decline of histone deacetylation and methylation in the chromatin of oligodenrocytes in the corpus callosum has been observed, an effect that could at least partially explain the age related reduction in the ability of the brain to repair myelin (Shen et al., 2008). Other drugs of abuse have been shown to have chromatin associated effects; repeated treatment with opioids has been shown to be associated with alterations of DNA methylation (Nielsen et al., 2009, 2010). However, no study to date has examined epigenetic mechanisms associated with myelin production during withdrawal from self-administered cocaine. This is an exploratory study designed to determine if DNA methylation changes in several genes whose products play a role in oligodendrocyte differentiation and myelin formation occur in response to cocaine treatment. Specifically, the purpose of this study was to determine chronic effects of cocaine administration followed by 1 or 30 days of abstinence on DNA methylation of three genes ( $M b p, P l p 1$, and Sox10) that encode MBP, PLP, and SOX10, respectively, proteins associated with myelin formation.

\section{MATERIALS AND METHODS ETHICS STATEMENT}

All experiments were carried out in accordance with the National Institutes of Health Guide for the Care and Use of Laboratory Animals (National Research Council, Institute of Laboratory Animal Research, Commission on Life Sciences, 1996) and with the approval of the Institutional Animal Care and Use Committee at University of Texas Medical Branch (Protocol \#88-03-039).

\section{ANIMALS}

Adult male Sprague-Dawley rats ( $n=19$; Harlan Sprague-Dawley Inc., Indianapolis, IN, USA), weighing 275-300 g at the start of the experiment were used. Upon arrival, rats were handled and given 4-5 days to acclimate to their environment. All animals were individually housed in a climate-controlled vivarium with a 12h light/dark cycle (lights on: 7:00 a.m., lights off: 7:00 p.m.) and given access to food (standard rat chow) and water ad libitum throughout the phases of the study (i.e., self-administration, forced abstinence, cue reactivity test).

\section{SELF-ADMINISTRATION PROCEDURES AND TISSUE DISSECTION}

Standard self-administration procedures were employed (Nic Dhonnchadha et al., 2009; Cunningham et al., 2011). Implantations of intravenous catheters with back mounts were performed under anesthesia with a cocktail containing $8.6 \mathrm{mg} / \mathrm{kg}$ of xylazine, $1.5 \mathrm{mg} / \mathrm{kg}$ of acepromazine, and $43 \mathrm{mg} / \mathrm{kg}$ of ketamine in bacteriostatic saline $(0.9 \% \mathrm{NaCl})$. Small incisions were made in the right posterior neck and just below the left shoulder blade to expose the right jugular vein and to insert the catheter base, respectively. A subcutaneous burrow was made between the two incisions, and the catheter apparatus was pulled through this burrow. The catheter was composed of Silastic ${ }^{\circledR}$ tubing (Dow Corning, Midland, Michigan, MI, USA) connected to a bent 22-gage metal cannula encased within a plastic screw connector (Plastics One, Roanoke, VA, USA) at one end and affixed with a small ball of aquarium sealant $3.5 \mathrm{~cm}$ from the other end. The distal end of the catheter was inserted into the jugular vein and pushed down until flush with the ball of aquarium sealant, terminating outside the right atrium. The catheter was secured to the vein with sutures (braided silk non-absorbable 4.0) on both sides of the aquarium sealant ball. The incision was then sutured (nylon non-absorbable 4.0). The cannula base was encased with dental acrylic and a small mesh circle $(3 \mathrm{~cm} \times 3 \mathrm{~cm}$; Polypro mesh $500 \mu \mathrm{m}$ ) affixed to the bottom, which was pulled thru the small incision in the back. The remaining opening was then sutured (nylon non-absorbable 4.0). Control rats were underwent sham surgery; rats were anesthetized and their jugular vein was exposed, but a catheter was not implanted (Nic Dhonnchadha et al., 2009; Cunningham et al., 2011).

Catheter patency was maintained by daily flushing with a solution of $0.1 \mathrm{~mL}$ bacteriostatic saline containing heparin sodium (10 U/mL, American Pharmaceutical Partners, IL, USA), streptokinase $(0.67 \mathrm{mg} / \mathrm{mL}$, Sigma, St. Louis, MO, USA), and ticarcillin disodium $(66.67 \mathrm{mg} / \mathrm{mL}$, Research Products International, Mt. Prospect, IL, USA) after each self-administration session. Proper catheter functioning was verified periodically throughout the experiment by intravenous (i.v.) administration of $10 \mathrm{mg} / \mathrm{mL}$ methohexital sodium (Monarch Pharmaceuticals Inc., Bristol, TN, USA), a dose sufficient to briefly anesthetize the animal only when administered i.v. The rats were allowed at least 5 days of recovery after surgery before initiation of self-administration training.

Standard operant chambers (Med-Associates, St. Albans, VT, USA) housed in ventilated sound-attenuating cubicles (MedAssociates) with fans to mask outside noise were utilized for selfadministration. Each chamber was equipped with two retractable response levers, a stimulus light above each response lever, and a house light opposite the levers. Infusions were delivered by a syringe within a motor-driven infusion pump (Med-Associates) located outside the chamber. The infusion pumps were connected to liquid swivels (Instech, Plymouth Meeting, PA, USA) which were fastened to the catheters via polyethylene 20 tubing encased inside a metal spring leash (Plastics One). Cocaine (dissolved in $0.9 \%$ saline; National Institute on Drug Abuse) or sham self-administration training consisted of 14 consecutive daily $3 \mathrm{~h}$ sessions (starting at 9:00 a.m.). Rats were trained to press the active lever to obtain a cocaine infusion $(0.75 \mathrm{mg} / \mathrm{kg} / 0.1 \mathrm{~mL}$, i.v. $)$ while each sham rat was placed in the operant chamber daily. Animals were not food-restricted or food-trained prior to commencement 
of cocaine self-administration and no drug-priming infusions were given during training. Scheduled completions on the active lever resulted in simultaneous activation of the house light and cue light, followed $1 \mathrm{~s}$ later by activation of the infusion pump. The $0.1 \mathrm{~mL}$ cocaine infusion was delivered over a $6 \mathrm{~s}$ period, after which the cue light and pump were inactivated simultaneously. The house light remained illuminated for a $20 \mathrm{~s}$ timeout period, during which lever presses had no scheduled consequences. Responses on the inactive lever also had no scheduled consequences. Animals were initially trained on a fixed ratio (FR) 1 schedule of cocaine reinforcement until they met a criterion of seven infusions/h for three consecutive days (with the additional criterion of $<10 \%$ variation in the total number of infusions received) and were moved to an FR 5 schedule of reinforcement for the training phase (14 days total).

At the end of the self-administration phase, the cocaine-trained rats were divided into two groups, 1 or 30 days of forced abstinence, matched for their mean drug intake during the self-administration phase. Each sham rat was randomly assigned to either 1 or 30 days of forced abstinence. The rats were returned to their home cages for the duration of the forced abstinence period. Thus, the design of the experiment resulted in the following groups designated by period of forced abstinence: sham rats with 1 day $(n=3)$ or 30 days $(n=4)$ of forced abstinence and cocaine self-administration rats with 1 day $(n=6)$ or 30 days $(n=6)$ of forced abstinence. On the designated day of withdrawal, rats were placed into the selfadministration chambers for $60 \mathrm{~min}$ and the stimulus complex previously paired with cocaine infusions (lights and motor pump) were presented contingent on a FR 1 schedule of reinforcement. Lever presses in the absence of drug reinforcement were recorded. Immediately following the test, rats were anesthetized with chloral hydrate $(400 \mathrm{mg} / \mathrm{kg}$, i.p.), sacrificed and the brains were dissected on ice. Brain tissue from the corpus callosum was frozen in liquid nitrogen and stored at $-80^{\circ} \mathrm{C}$. DNA was isolated from the brain tissue using the Gentra Purgene DNA isolation method (Qiagen, Valencia, CA, USA) according to the manufacturer's protocol.

\section{PRIMER DESIGN AND PCR AMPLIFICATION}

As reported previously (Nielsen et al., 2009, 2010), possible methylation patterns and bisulfite-altered nucleotides were designed using the Methyl Primer Express 1.0 software (ABI). Predicted bisulfite-treated and untreated sequences were exported to Vector NTI Advance 11 (Invitrogen, Carlsbad, CA, USA). Forward and reverse primers were designed with Methyl Primer Express 1.0 (Life Technologies Corp, Carlsbad, CA, USA) or with Vector NTI Advance 11, and synthesized (Midland Reagent Co., Midland, TX, USA). Regions in the promoters of each gene were amplified with the primers and conditions listed in Table $\mathbf{1 .}$

\section{ANALYSIS OF THE Mbp PROMOTER REGION}

Three sets of DNA primers were used to assay CpG sites around the transcription start site (TSS) for DNA methylation levels of the $M b p$ gene promoter region. The TSS is based on the sequence of the RefSeq gene NM_030990 and is located at chrX: 124,488,627$124,503,639$. Nucleotide numbering of the $M b p$ promoter region is relative to the location of the $\mathrm{A}$ of the translation start codon
ATG of $M b p$ with the TSS is located at -77. Primers M-RATMBP$4 \mathrm{~F}$ and M-RATMBP-4R (Table 1) amplified the promoter region of $M b p$ from -193 to +10 . This amplicon was used to evaluate the $-138,-123,-111,-101,-58$, and -55 CpG sites. Primers MRATMBP-6F and M-RATMBP-6R amplified the region from -54 to +264 and evaluated the $-16,+28,+33,+76,+107,+126$, $+130,+141,+155,+163,+186$, and +191 sites. Primers MRATMBP-3F and M-RATMBP-3R amplified the DNA from +570 to +886 and evaluated the $+606,+624,+646,+693,+708,+794$, and $+838 \mathrm{CpG}$ sites. Sequencing was performed in both directions using the amplification primers. The $\mathrm{CpG}$ sites located between the $6 \mathrm{~F} / 6 \mathrm{R}$ and the $3 \mathrm{~F} / 3 \mathrm{R}$ amplicons $(+330,+341,+347,+369,+404$, $+529,+549$, and +554$)$ were not evaluated.

\section{ANALYSIS OF THE PIp1 PROMOTER REGION}

DNA methylation levels of specific CpG sites in the $P l p 1$ promoter region were determined in a similar manner to that which was done for Mbp. The Mbp TSS is based on the sequence of the RefSeq gene NM_030990 located at chrX: 124,488,627-124,503,639, and is located at -122 relative to the A of the ATG translation start codon. Relatively few CpG sites are located upstream of the TSS of the $P l p 1$ gene. The closest CpG site upstream of the Plp1 gene is located 342 nucleotides from the TSS at -464 . The first six CpG sites downstream of the TSS are to be found at $-51,+64$, $+453,+517,+538,579$, and +603 nucleotides. Two amplicons were designed to cover these six $\mathrm{CpG}$ sites. The first amplicon was used to assess the -51 and $+64 \mathrm{CpG}$ sites using primers MRATPLP1-5F and M-RATPLP1-5R (Table 1), which amplified the region from -148 to +238 . Sequencing was performed in both directions using these primers. The second amplicon examined the $+453,+517,+538,579$, and $+603 \mathrm{CpG}$ sites using primers M-RATPLP1-3F and M-RATPLP1-3R, which amplified the region of +398 to +747 . Sequencing was done in both directions using the internal primers M-RATPLP1-4F and M-RATPLP1-4R.

\section{ANALYSIS OF THE Sox10 PROMOTER REGION}

Two genomic forms of the Sox10 gene are annotated in GenBank. The upstream TSS form (NM_019193.1) of Sox10 has five exons and the downstream TSS form (NM_019193) has four exons, with the translation start codon located in the second and third exon, respectively. Both these forms of Sox10 have similar counterparts in the mouse genome (uc007wsv.1 and NM_011437.1). We analyzed the DNA methylation of CpG sites in the upstream promoter region of the Sox10 gene corresponding to NM_019193.1. The TSS of NM_019193.1 is at chr7: 117,149,939, which is located 2654 nucleotides upstream of the A of the translation start codon. The CpG sites of the upstream TSS of Sox10 are designated relative to their location from NM_019193.1 TSS, which is designated as +1 . The region immediately upstream of the downstream TSS (NM_019193) is not annotated in GenBank. We attempted to sequence this region, but were unable to obtain readable sequence data. Therefore, we were unable to analyze the region surrounding the Sox10 downstream TSS for DNA methylation levels. Primers M-RATSOX10-3F and M-RATSOX10-3R were used to amplified the Sox10 upstream promoter region from -272 to +90 . Using this amplicon we were able to evaluate the $-189,-172,-142$, $-93,-78,-62,-49 \mathrm{CpG}$ sites. The next CpG site is located 42 
Table 1 | Primers used for the amplification and sequencing of the bisulfate-treated DNA.

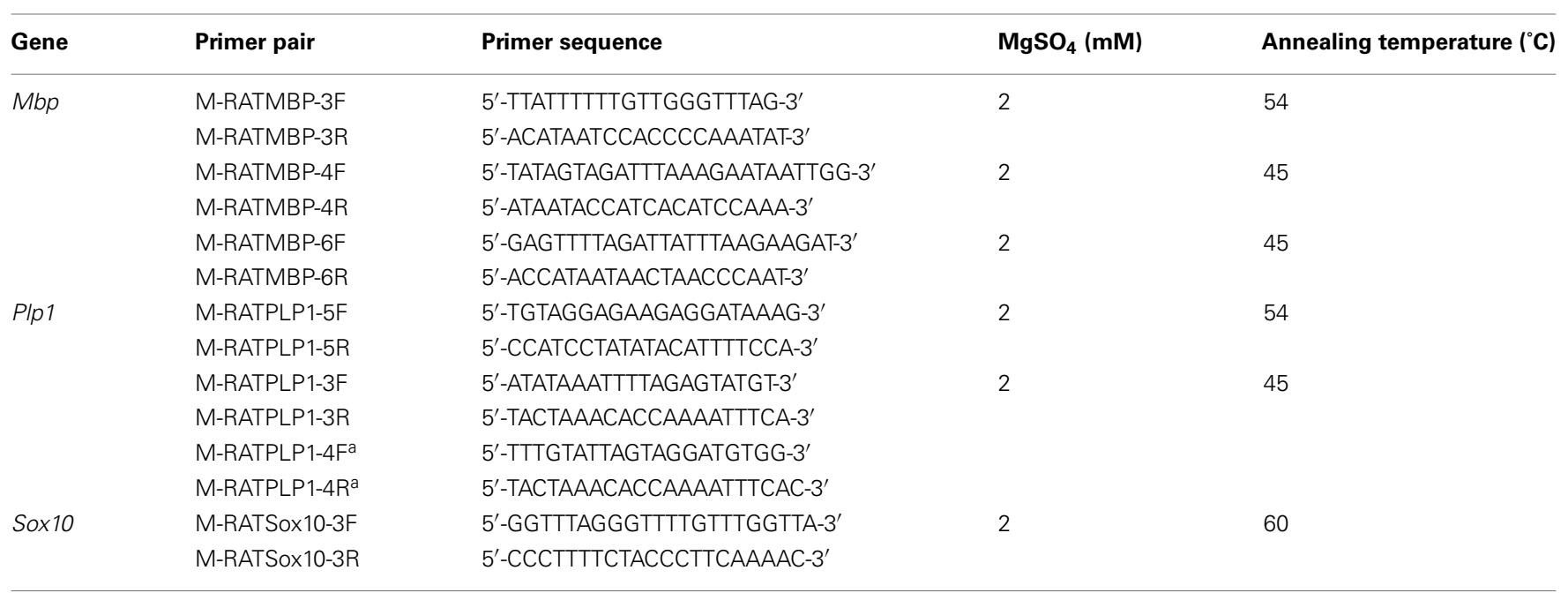

${ }^{a}$ Primers used for the sequencing of the PCR product of the amplification with primers. M-RATPPL 1-3F and M-RATPPL 1-3R.

nucleotides past the TSS (not evaluated in this study). Methylation data was obtained only from sequencing with the forward primer.

\section{DETERMINATION OF PERCENT METHYLATED CYTOSINE}

Percent cytosine methylation was determined as previously described (Nielsen et al., 2009). Briefly, genomic DNA (300 ng) was treated with sodium bisulfite using the EZ-96 DNA Methylation Kit D5004 (Zymo Research, Orange, CA, USA) and amplified (Nielsen et al., 2009). DNA was amplified with the primer sets listed in Table 1. Amplification was performed with $1 \mu \mathrm{L}$ bisulfitetreated DNA, $1 \mu \mathrm{M}$ of each primer, $250 \mu \mathrm{M}$ each of dATP, dCTP, dGTP, and TTP, $50 \mathrm{mM} \mathrm{KCl,} 4 \mathrm{mM} \mathrm{MgCl}_{2}, 0.625$ units AmpliTaq Gold $^{\circledR}$ (Applied Biosystems), and $10 \mathrm{mM}$ Tris- $\mathrm{HCl}(\mathrm{pH} \mathrm{8.3)} \mathrm{in}$ $25 \mu \mathrm{L}$. Amplification consisted of $5 \mathrm{~min}$ at $95^{\circ} \mathrm{C}, 40$ cycles of $15 \mathrm{~s}$ at $95^{\circ} \mathrm{C}, 15 \mathrm{~s}$ at the appropriate annealing temperature, and $30 \mathrm{~s}$ at $72^{\circ} \mathrm{C}$, followed by a final elongation step at $72^{\circ} \mathrm{C}$ for $7 \mathrm{~min}$. Purified DNA fragments were sequenced at GENEWIZ, Inc. (South Plainfield, NJ, USA) on an ABI 3730 XL sequencer (Applied Biosystems). Trace files (.ab1) were analyzed using the ESME version 3.2.1 software from Epigenomics AG (Berlin, Germany; Lewin et al., 2004). The percent methylation calls by the ESME were reviewed by two independent researchers who visually inspected all the methylation calls using the associated electropherograms generated by the ESME software.

\section{GLOBAL DNA METHYLATION}

Percent of cytosine methylation was determined in duplicate using the Methylamp Global DNA Methylation Quantification Ultra Kit (Epigentek Group Inc., Brooklyn, NY, USA) according to manufacturer's recommendations. Briefly, 200 ng DNA was immobilized to each well, which had been coated with a DNA affinity compound. The methylated fraction of the rat DNA was quantitated using a 5-methylcytosine monoclonal antibody in an ELISAlike reaction. The levels of methylated DNA were determined using an internal standard curve of OD intensity at $450 \mathrm{~nm}$ on a
VICTOR X5 2030 Multilabel plate reader (PerkinElmer, Waltham, MA, USA).

\section{STATISTICAL ANALYSIS}

The total cocaine intake across the 14 days of self-administration for the rats assigned to 1 and 30 days of forced abstinence was analyzed using the Student's $t$-test (two-tailed). Global methylation was determined for each sample in duplicate. Comparisons of global methylation were made using the Student's $t$-test (twotailed). For the determination of percent methylation at each $\mathrm{CpG}$ site, DNA methylation was quantified for $M b p$ and $P l p 1$ in each direction separately to control for sequencing and PCR artifacts. The mean of the forward and reverse values were calculated for each CpG site of $M b p$ and $P l p 1$ for each sample. Data was obtained only in the forward direction for the analysis of the CpGs in the promoter region of Sox 10 . We performed a repeated measures analysis of variance to determine if the pattern of mean methylation levels across each gene was significantly different between cocaine and sham controls in either the 1 or 30 days of forced abstinence. A two-tailed $t$-test was performed using these mean values to examine differences between groups at each $\mathrm{CpG}$ site. Individual results were evaluated for significance at $p \leq 0.05$. Data for the individual $\mathrm{CpG}$ sites is reported as point-wise or experiment-wise significance levels. To determine experiment-wise significance levels, a Bonferroni correction was applied.

\section{RESULTS}

\section{COCAINE SELF-ADMINISTRATION}

Rats $(n=19)$ readily acquired cocaine self-administration $(0.75 \mathrm{mg} / \mathrm{kg} / 0.1 \mathrm{~mL}$ infusion $)$ in daily 3 -h sessions to stability (i.e., seven infusions/h on an FR 5 schedule for at least three sessions) and displayed $<10 \%$ variation in the number of infusions received (i.e., cocaine intake) by training day 14 of the self-administration phase. Total cocaine intake across the 14 days of self-administration for the rats assigned to 1 day $(346.5 \pm 21.3 \mathrm{mg} / \mathrm{kg})$ and 30 days of forced 
abstinence $(291.1 \pm 34.1 \mathrm{mg} / \mathrm{kg})$ were not statistically different $(p=0.204)$.

\section{CpG DNA METHYLATION IN THE Mbp GENE PROMOTER REGION}

The methylation of DNA at $24 \mathrm{CpG}$ sites in the Mbp gene promoter region was quantitated in the corpus callosum of rats from the four treatment groups. The DNA methylation pattern of these $24 \mathrm{Mbp}$ CpG sites combined was evaluated for differences between groups (Figures 1A,B). There was no significant difference in the pattern of mean DNA methylation at the $24 \mathrm{Mbp}$ CpG sites seen at either 1 or 30 days of forced abstinence following cocaine selfadministration versus the respective sham controls after adjusting for multiple testing.

\section{CpG DNA METHYLATION IN THE PIp1 GENE PROMOTER REGION}

The methylation of DNA at seven CpG sites in the PIp 1 promoter region was quantitated in the corpus callosum of rats from the four treatment groups. The DNA methylation pattern of the combined CpG sites of Plp1 was assessed for differences between groups (Figures 1C,D). There was no significant difference in the pattern of mean DNA methylation of these seven Plp1 CpG sites seen at either 1 or 30 days of forced abstinence from cocaine selfadministration versus the respective sham controls after adjusting for multiple testing.

\section{CpG DNA METHYLATION IN THE SOX10 GENE PROMOTER REGION}

The methylation of DNA at seven CpG sites in the Sox 10 promoter region was quantitated in the corpus callosum of rats from the four treatment groups (Figures 1E,F). At these seven Sox10 CpG sites, the pattern of mean DNA methylation was assessed. On day 1 of forced abstinence a trend was observed for a decrease in the mean DNA methylation pattern in the cocaine self-administered rats compared with the sham controls $(p=0.06$, Figure 1E). A significantly different mean DNA methylation pattern in corpus callosum was observed in rats following 30 days of forced abstinence from cocaine self-administration relative to respective sham controls (experiment-wise $p<0.001$, Figure 1F). The mean level of methylation of the seven sites combined was $44 \%$ lower in rats exposed to 30 days of forced abstinence $(38.2 \%)$ relative to sham control rats $(68.5 \%)$. The difference in mean level of methylation between the cocaine and sham groups was significantly higher at 30 days relative to 1 day of forced abstinence (experiment-wise $p<0.001)$. In addition, we found the 30-day sham control rats expressed a different mean DNA methylation pattern relative to the 1-day sham control rats. In the sham control rats, the mean level of methylation was 33\% higher in rats exposed to 30 days of forced abstinence $(68.5 \%)$ relative to 1 day of forced abstinence $(51.4 \% ; p=0.016)$. In the cocaine self-administration rats, the mean level of methylation was not significantly different between the rats exposed to 1 day (40.7\%) or 30 days $(38.2 \%)$ of forced abstinence.

Since differences were found between the DNA methylation patterns of the Sox 10 promoter region, the individual CpG sites were assessed for differences in methylation levels between rats in the self-administration and sham control conditions exposed to either 1 or 30 days of forced abstinence. On day 1 of forced abstinence, the $-62 \mathrm{CpG}$ site was hypermethylated in the forced abstinence versus sham controls. The methylation level of the $-62 \mathrm{CpG}$ was $46.17 \%$ in the 1 day of forced abstinence compared to $61.7 \%$ in the respective sham group (experiment-wise $p=0.022$, point-wise $p=0.003$; Figure 1E). In contrast, the $-189,-142,-93$, and -62 $\mathrm{CpG}$ sites were hypomethylated at 30 days of forced abstinence versus sham controls (Figure 1F). The methylation level of the -189 site was $19.0 \pm 2.8 \%$ in the 30 days of forced abstinence group versus $54.3 \pm 17.3 \%$ in the respective sham group (point-wise $p=0.036), 25.4 \pm 2.7$ versus $64.3 \pm 18.2 \%$ for the $-142 \mathrm{CpG}$ site (point-wise $p=0.30$ ), $85.7 \pm 12.4$ versus $52.0 \pm 6.4 \%$ for the -93 site (point-wise $p=0.047$ ), and $40.0 \pm 4.5$ versus $74.3 \pm 10.2 \%$ (point-wise $p=0.019$ ) for the -62 site.

There was no correlation between the total cocaine intake and DNA methylation at any CpG site for the three genes studied under each condition (data not shown).

\section{GLOBAL DNA METHYLATION}

Analysis of global DNA methylation was performed on DNA from the corpus callosum from rats to assess if any of our results may be due to a change in overall DNA methylation in our sample. No difference in global DNA methylation levels were found between 1 day of forced abstinence $(7.7 \pm 0.8 \%)$ and the respective sham controls $(6.1 \pm 0.5 \%)$, or between 30 days of forced abstinence $(6.3 \pm 0.5 \%)$ and sham control $(6.3 \pm 0.4 \%)$ groups.

\section{DISCUSSION}

The overall finding of this study is that forced abstinence from cocaine self-administration in rats is associated with differential changes in DNA methylation of the Sox10 gene in the corpus callosum. In particular, significant hypomethylation of the Sox 10 gene emerged at 30 days of forced abstinence from cocaine self-administration.

This study was initiated to determine whether forced abstinence from cocaine self-administration was associated with changes in DNA methylation in several myelin genes in white matter, a question which was driven by the consistent findings of altered white matter in cocaine dependent subjects as measured by DTI (Moeller et al., 2005, 2007; Lim et al., 2008; Ma et al., 2009; Lane et al., 2010), white matter volume differences in cocaine dependent subjects (Bartzokis et al., 2002), and the association between white matter integrity and better treatment outcome (Xu et al., 2010b). Similar decreases in white matter integrity have been demonstrated in rats exposed to continuous subcutaneous administration of cocaine via osmotic mini pump ( $40 \mathrm{mg} / \mathrm{kg} /$ day cocaine for 28 days); this study also identified a concomitant decrease in MBP (Narayana et al., 2009). In the present study, no changes in DNA methylation were observed in either the $M b p$ or Plp1 promoter regions following withdrawal from self-administration of cocaine, which might have been expected given the previous observations. However, these two protocols of cocaine administration result in very different pharmacokinetic and pharmacodynamic profiles, and it will be important to establish a comprehensive profile of gene changes in corpus callosum, which could contribute to loss of white matter integrity following cocaine self-administration.

Oligodendrocytes wrap around and insulate neurons to increase the propagation of neuronal action potentials. The oligodendrocyte wraps around central nervous system (CNS) neurons to form the myelin sheath, which is primarily composed 


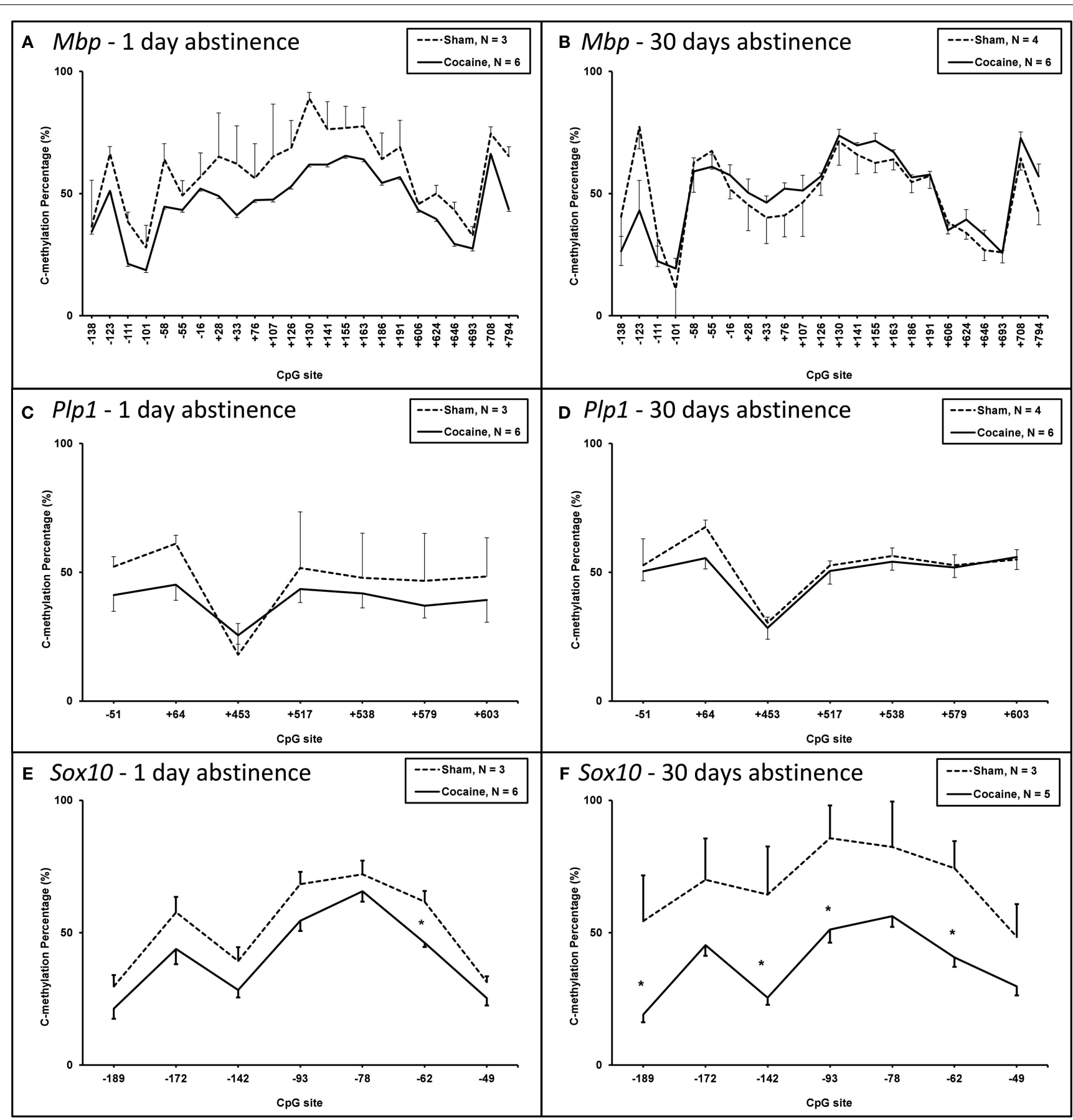

FIGURE 1 | Mean CpG dinucleotide methylation levels in the promoter region of the genes coding for the major myelin proteins Mbp and PIp1, and the transcription factor Sox 10 in cocaine-treated and control rats.

(A) Mbp methylation in the 1 day abstinence groups. (B) Mbp methylation in the 30 day abstinence groups. (C) P/p 1 methylation in the 1 day abstinence groups. (D). Plp1 methylation in the 30 day abstinence groups. (E) Sox 10 methylation in the 1 day abstinence groups. $-62 \mathrm{CpG}$ site: Sham $=61.7 \%$, cocaine $=46.17 \%$, point-wise $p=0.047$; experiment-wise $p=0.022$, point-wise $p=0.003$. (F) Sox 10 methylation in the 30 day abstinence groups. -189 CpG site: Sham $=54.3 \%$, cocaine $=19.0 \%$; point-wise $p=0.036$ : -142 CpG site: Sham $=64.3 \%$, cocaine $=25.4 \%$; point-wise $p=0.030:-93 \mathrm{CpG}$ site: Sham $=85.7 \%$, cocaine $=52.0 \%$; point-wise $p=0.047:-62$ CpG site: Sham $=74.3 \%$, cocaine $=40.0 \%$. point-wise $p=0.019$. ${ }^{*} p<0.05$. Error bars represent SEM. of $M b p$ and proteolipid protein (PLP/DM20; lipophilin). Oligodendrocyte maturation proceeds from the differentiation of neural stem cells into immature oligodendrocytes, which subsequently form mature myelinating oligodendrocytes. The initial differentiation is determined, in part, by the oligodendrocytespecific transcription factor Sox10, which drives oligodendrocyte 
fate selection and maturation in concert with other transcription factors (Wegner, 2000; Gokhan et al., 2005).

In one study of patients with glioblastoma, hypermethylation of two specific CpG sites in the Sox10 gene were found to be associated with reduced gene expression and shorter overall survival (Etcheverry et al., 2010), consistent with other studies showing that the presence of oligodendroglial differentiation in glioblastoma patients is associated with longer survival (Salvati et al., 2009). In our study, hypermethylation of Sox10 was observed in the 30 day abstinent sham group compared to the 1 day of abstinence sham group. The difference between the two groups appears to be due to an increase in methylation in the sham group between 1 day of abstinence and 30 days of abstinence, with no increase in methylation between 1 and 30 days of abstinence in the cocaine group. One possible explanation for this difference is that cocaine administration blocked the increase in Sox 10 methylation seen over time in rodents during normal maturation. Previous studies have shown that DNA methylation in the brain changes with age in rodents (reviewed in Takasugi, 2011). This would be consistent with human imaging studies showing an inverted $\mathrm{U}$ shaped curve for the relationship between white matter integrity as measured by FA on DTI and age (Hasan et al., 2009).

Our results show that the overall level of methylation of the Sox10 gene promoter region was reduced in the corpus callosum after 30 days of abstinence from cocaine compared to levels found after 1 day abstinence from cocaine. The hypermethylation of Sox10 appears to have occurred by the first day of abstinence in the cocaine self-administered rats, although this was only a trend statistically. This hypomethylation may be in response to cessation of cocaine treatment or to oligodendrocyte damage. Hypomethylation of specific CpG sites in the Sox10 promoter region in the corpus callosum in response to cocaine treatment could alter the expression of Sox10 and contribute to altered white matter in cocaine dependence. Alternatively, cocaine hypomethylation of Sox10 may result in aberrant gene expression that could lead to neurotoxicity and a decrease in white matter integrity. Cocaine has been reported to increase DNA methylation of the promoter region of other genes. Increased DNA methylation of the promoter region of the $C d k l 5$ gene in the striatum in rats was found after cocaine treatment (Carouge et al., 2010). In the nucleus accumbens of mice, cocaine has been shown to induce Dnmt3a and Dnmt3b expression, to increase methylation of the promoter region of the $P p 1 c$ gene, and to decrease the methylation of the FosB gene promoter region, thereby increasing $\mathrm{MeCP} 2$ binding and decreasing Pplc expression (Anier et al., 2010). Cocaine treatment of pregnant dams was reported to induce hypermethylation of specific regions in the promoter of the $P K C \varepsilon$ gene in the developing fetal heart (Zhang et al., 2007, 2009).

Cocaine has also been shown to alter chromatin remodeling. Both $c F o s$ and $\Delta F o s B$ expression are activated by cocaine (Graybiel et al., 1990; Young et al., 1991; McClung and Nestler, 2003). This has been shown to occur in parallel with chromatin remodeling. A single injection of cocaine caused chromatin remodeling at the cFos promoter and chronic cocaine caused chromatin remodeling at the $\Delta$ FosB promoter in the striatum (Kumar et al., 2005). Acute and chronic cocaine cause hypomethylation of the Fos $B$ promoter, decreased MeCP2 binding, and upregulated Fos $B$ expression in the NAc (Anier et al., 2010). The micoRNA-212 (miR-212) was recently reported to be upregulated in response to cocaine in the striatum of rats, leading to an amplification of the stimulatory effects of cocaine on CREB signaling (Hollander et al., 2010). In the nucleus accumbens of rats, repeated cocaine administration was reported to persistently decrease histone H3 lysine 9 trimethylation, predominately in intergenic repeat regions, possibly contributing to increased gene expression (Maze et al., 2011).

The role of 5-hydroxymethylcytosine $(5-\mathrm{hmC})$ in the regulation of gene expression is currently under investigation in a number of studies. For example, $5-\mathrm{hmC}$ has been suggested to play a role in fetal development of the heart, lung, and brain (Kinney et al., 2011). The bisulfite conversion technique we used to measure DNA methylation cannot differentiate between 5-methylcytosine $(5-\mathrm{mC})$ and $5-\mathrm{hmC}$. However, the contribution of 5-hmC is small. $5-\mathrm{mC}$ to $5-\mathrm{hmC}$ has been shown to be approximately 10:1 in murine embryonic stem cells (Tahiliani et al., 2009), and in Purkinje or granule cells 0.6 and $0.2 \%$, respectively, of the nucleotide pool is 5-hmC (Kriaucionis and Heintz, 2009).

The results of this study indicate that it will be important in future studies to assess changes in gene expression during withdrawal from cocaine self-administration. This would provide further evidence as to the role of DNA methylation in the maturation and myelination. More extensive examination of the time course of DNA methylation changes seen during withdrawal from cocaine self-administration will prove additional valuable information.

There are a number of limitations of this study. The primary limitation was that significant changes in mean DNA methylation did not appear until after 30 days of abstinence. This raises the question of the functional significance of these changes as to our knowledge prior research has not specifically determined effects of age related changes in DNA methylation of Sox10 on white matter structure. Another limitation is the relatively small number of rodents, which may have contributed to the lack of statistically significant differences in DNA methylation of Mbp and Plp1. Because of these limitations, the results of this study should be considered preliminary. In spite of these limitations, this is the first study to show differences in DNA methylation in white matter between cocaine self-administration and sham rodents.

In summary, this study provides initial evidence that 30 days of forced abstinence from cocaine self-administration was found to be associated with a differential profile of DNA methylation in a white matter related gene in the corpus callosum relative to sham controls. One potential implication of these findings is that such epigenetic changes contribute to the toxicity of cocaine on myelin structure. Future studies of the relationship between quantity and duration of cocaine use on white matter and gene expression are needed, as are studies on potential pharmacotherapies that could reduce these effects.

\section{ACKNOWLEDGMENTS}

This research was supported by the National Institute on Drug Abuse grants R21DA020117-02S1 (David A. Nielsen, Kosten, CoPIs), P20 DA024157 (Kathryn A. Cunningham, F. Gerard Moeller), R01 DA006511 (Kathryn A. Cunningham), K02 DA000403 (F. Gerard Moeller), K05 DA020087 (Kathryn A. Cunningham), the Veterans Health Administration, and the David Toomim Fund. 


\section{REFERENCES}

Anier, K., Malinovskaja, K., AonurmHelm, A., Zharkovsky, A., and Kalda, A. (2010). DNA methylation regulates cocaine-induced behavioral sensitization in mice. Neuropsychopharmacology 35, 2450-2461.

Bartzokis, G., Beckson, M., Lu, P. H., Edwards, N., Bridge, P., and Mintz, J. (2002). Brain maturation may be arrested in chronic cocaine addicts. Biol. Psychiatry 51, 605-611.

Carouge, D., Host, L., Aunis, D., Zwiller, J., and Anglard, P. (2010). CDKL5 is a brain $\mathrm{MeCP} 2$ target gene regulated by DNA methylation. Neurobiol. Dis. 38, 414-424.

Cunningham, K. A., Fox, R. G., Anastasio, N. C., Bubar, M. J., Stutz, S. J., Moeller, F. G., Gilbertson, S. R., and Rosenzweig-Lipson, S. (2011). Selective serotonin 5-HT(2C) receptor activation suppresses the reinforcing efficacy of cocaine and sucrose but differentially affects the incentive-salience value of cocainevs. sucrose-associated cues. $\mathrm{Neu}$ ropharmacology 61, 513-523.

Etcheverry, A., Aubry, M., De Tayrac, M., Vauleon, E., Boniface, R., Guenot, F., Saikali, S., Hamlat, A., Riffaud, L., Menei, P., Quillien, V., and Mosser, J. (2010). DNA methylation in glioblastoma: impact on gene expression and clinical outcome. BMC Genomics 11, 701. doi:10.1186/1471-2164-11-701

Gokhan, S., Marin-Husstege, M., Yung, S. Y., Fontanez, D., CasacciaBonnefil, P., and Mehler, M. F. (2005). Combinatorial profiles of oligodendrocyte-selective classes of transcriptional regulators differentially modulate myelin basic protein gene expression. J. Neurosci. 25, 8311-8321.

Graybiel, A. M., Moratalla, R., and Robertson, H. A. (1990). Amphetamine and cocaine induce drugspecific activation of the c-fos gene in striosome-matrix compartments and limbic subdivisions of the striatum. Proc. Natl. Acad. Sci. U.S.A. 87, 6912-6916.

Harauz, G., Ladizhansky, V., and Boggs, J. M. (2009). Structural polymorphism and multifunctionality of myelin basic protein. Biochemistry 48, 8094-8104.

Hasan, K. M., Iftikhar, A., Kamali, A., Kramer, L. A., Ashtari, M., Cirino, P. T., Papanicolaou, A. C., Fletcher, J. M., and Ewing-Cobbs, L. (2009). Development and aging of the healthy human brain uncinate fasciculus across the lifespan using diffusion tensor tractography. Brain Res. 1276, 67-76.
Hollander, J. A., Im, H. I., Amelio, A. L., Kocerha, J., Bali, P., Lu, Q., Willoughby, D., Wahlestedt, C., Conkright, M. D., and Kenny, P. J. (2010). Striatal microRNA controls cocaine intake through CREB signalling. Nature 466, 197-202.

Kinney, S. M., Chin, H. G., Vaisvila, R., Bitinaite, J., Zheng, Y., Esteve, P. O., Feng, S., Stroud, H., Jacobsen, S. E., and Pradhan, S. (2011). Tissue-specific distribution and dynamic changes of 5-hydroxymethylcytosine in mammalian genomes. J. Biol. Chem. 286, 24685-24693.

Kriaucionis, S., and Heintz, N. (2009). The nuclear DNA base 5-hydroxymethylcytosine is present in Purkinje neurons and the brain. Science 324, 929-930.

Kristiansen, L. V., Bannon, M. J., and Meador-Woodruff, J. H. (2009). Expression of transcripts for myelin related genes in postmortem brain from cocaine abusers. Neurochem. Res. 34, 46-54.

Kumar, A., Choi, K. H., Renthal, W., Tsankova, N. M., Theobald, D. E., Truong, H. T., Russo, S. J., Laplant, Q., Sasaki, T. S., Whistler, K. N., Neve, R. L., Self, D. W., and Nestler, E. J. (2005). Chromatin remodeling is a key mechanism underlying cocaineinduced plasticity in striatum. $\mathrm{Neu}$ ron 48, 303-314.

Lane, S. D., Steinberg, J. L., Ma, L., Hasan, K. M., Kramer, L. A., Zuniga, E. A., Narayana, P. A., and Moeller, F. G. (2010). Diffusion tensor imaging and decision making in cocaine dependence. PLOS ONE 5, el1591. doi:10.1371/journal.pone.0011591

Lewin, J., Schmitt, A. O., Adorjan, P., Hildmann, T., and Piepenbrock, C. (2004). Quantitative DNA methylation analysis based on four-dye trace data from direct sequencing of PCR amplificates. Bioinformatics 20, 3005-3012.

Lim, K. O., Choi, S. J., Pomara, N., Wolkin, A., and Rotrosen, J. P. (2002). Reduced frontal white matter integrity in cocaine dependence: a controlled diffusion tensor imaging study. Biol. Psychiatry 51, 890-895.

Lim, K. O., Wozniak, J. R., Mueller, B. A., Franc, D. T., Specker, S. M., Rodriguez, C. P., Silverman, A. B., and Rotrosen, J. P. (2008). Brain macrostructural and microstructural abnormalities in cocaine dependence. Drug Alcohol Depend. 92, 164-172.

Ma, L., Hasan, K. M., Steinberg, J. L., Narayana, P. A., Lane, S. D., Zuniga,
E. A., Kramer, L. A., and Moeller, F. G. (2009). Diffusion tensor imaging in cocaine dependence: regional effects of cocaine on corpus callosum and effect of cocaine administration route. Drug Alcohol Depend. 104, 262-267.

Maze, I., Feng, J., Wilkinson, M. B., Sun, H., Shen, L., and Nestler, E. J. (2011). Cocaine dynamically regulates heterochromatin and repetitive element unsilencing in nucleus accumbens. Proc. Natl. Acad. Sci. U.S.A. 108, 3035-3040.

McClung, C. A., and Nestler, E. J. (2003). Regulation of gene expression and cocaine reward by CREB and DeltaFosB. Nat. Neurosci. 6, 1208-1215.

Moeller, F. G., Hasan, K. M., Steinberg, J. L., Kramer, L. A., Dougherty, D. M., Santos, R. M., Valdes, I., Swann, A. C., Barratt, E. S., and Narayana, P. A. (2005). Reduced anterior corpus callosum white matter integrity is related to increased impulsivity and reduced discriminability in cocainedependent subjects: diffusion tensor imaging. Neuropsychopharmacology 30, 610-617.

Moeller, F. G., Hasan, K. M., Steinberg, J. L., Kramer, L. A., Valdes, I., Lai, L. Y., Swann, A. C., and Narayana, P. A. (2007). Diffusion tensor imaging eigenvalues: preliminary evidence for altered myelin in cocaine dependence. Psychiatry Res. 154, 253-258.

Narayana, P. A., Ahobila-Vajjula, P., Ramu, J., Herrera, J., Steinberg, J. L., and Moeller, F. G. (2009). Diffusion tensor imaging of cocainetreated rodents. Psychiatry Res. 171, 242-251.

National Research Council, Institute of Laboratory Animal Research, Commission on Life Sciences. (1996). Guide for the Care and Use of Laboratory Animals. Washington, DC: The National Academies Press.

Nave, K. A. (2010). Myelination and support of axonal integrity by glia. Nature 468, 244-252.

Nic Dhonnchadha, B. A., Fox, R G., Stutz, S. J., Rice, K. C., and Cunningham, K. A. (2009). Blockade of the serotonin 5-HT2A receptor suppresses cue-evoked reinstatement of cocaine-seeking behavior in a rat self-administration model. Behav. Neurosci. 123, 382-396.

Nielsen, D. A., Hamon, S., Yuferov, V., Jackson, C., Ho, A., Ott, J., and Kreek, M. J. (2010). Ethnic diversity of DNA methylation in the OPRM1 promoter region in lymphocytes of heroin addicts. Hum. Genet. 127, 639-649.
Nielsen, D. A., Yuferov, V., Hamon, S., Jackson, C., Ho, A., Ott, J., and Kreek, M. J. (2009). Increased OPRM1 DNA methylation in lymphocytes of methadone-maintained former heroin addicts. Neuropsychopharmacology 34, 867-873.

Salvati, M., Formichella, A. I., D'Elia, A., Brogna, C., Frati, A., Giangaspero, F., Delfini, R., and Santoro, A. (2009). Cerebral glioblastoma with oligodendrogliomal component: analysis of 36 cases. J. Neurooncol. 94, 129-134.

Shen, S., Liu, A., Li, J., Wolubah, C. and Casaccia-Bonnefil, P. (2008). Epigenetic memory loss in aging oligodendrocytes in the corpus callosum. Neurobiol. Aging 29, 452-463.

Stolt, C. C., Rehberg, S., Ader, M., Lommes, P., Riethmacher, D., Schachner, M., Bartsch, U., and Wegner, M. (2002). Terminal differentiation of myelin-forming oligodendrocytes depends on the transcription factor Sox10. Genes Dev. 16, 165-170.

Tahiliani, M., Koh, K. P., Shen, Y., Pastor, W. A., Bandukwala, H., Brudno, Y., Agarwal, S., Iyer, L. M., Liu, D. R., Aravind, L., and Rao, A. (2009). Conversion of 5-methylcytosine to 5-hydroxymethylcytosine in mammalian DNA by MLL partner TET1. Science 324, 930-935.

Takada, N., Kucenas, S., and Appel, B. (2010). Sox10 is necessary for oligodendrocyte survival following axon wrapping. Glia 58, 996-1006.

Takasugi, M. (2011). Progressive age-dependent DNA methylation changes start before adulthood in mouse tissues. Mech. Ageing Dev. 132, 65-71.

Wegner, M. (2000). Transcriptional control in myelinating glia: the basic recipe. Glia 29, 118-123.

Xu, J., Devito, E. E., Worhunsky, P. D., Carroll, K. M., Rounsaville, B. J., and Potenza, M. N. (2010a). White matter integrity is associated with treatment outcome measures in cocaine dependence. Neuropsychopharmacology 35, 1541-1549.

Xu, Q., Zhou, Y., Li, Y. S., Cao, W. W., Lin, Y., Pan, Y. M., and Chen, S. D. (2010b). Diffusion tensor imaging changes correlate with cognition better than conventional MRI findings in patients with subcortical ischemic vascular disease. Dement. Geriatr. Cogn. Disord. 30, 317-326. 
Young, S. T., Porrino, L. J., and Iadarola, M. J. (1991). Cocaine induces striatal c-fos-immunoreactive proteins via dopaminergic D1 receptors. Proc. Natl. Acad. Sci. U.S.A. 88, 1291-1295.

Zhang, H., Darwanto, A., Linkhart, T. A., Sowers, L. C., and Zhang, L. (2007). Maternal cocaine administration causes an epigenetic modification of protein kinase Cepsilon gene expression in fetal rat heart. Mol. Pharmacol. 71, 1319-1328.
Zhang, H., Meyer, K. D., and Zhang, L. (2009). Fetal exposure to cocaine causes programming of Prkce gene repression in the left ventricle of adult rat offspring. Biol. Reprod. 80, 440-448.

Conflict of Interest Statement: The authors declare that the research was conducted in the absence of any commercial or financial relationships that could be construed as a potential conflict of interest.
Received: 17 May 2012; paper pending published: 22 May 2012; accepted: 26 May 2012; published online: 14 June 2012.

Citation: Nielsen DA, Huang W, Hamon SC, Maili L, Witkin BM, Fox RG, Cunningham KA and Moeller FG (2012) Forced abstinence from cocaine selfadministration is associated with DNA methylation changes in myelin genes in the corpus callosum: a preliminary study. Front. Psychiatry 3:60. doi: 10.3389/fpsyt.2012.00060
This article was submitted to Frontiers in Addictive Disorders, a specialty of Frontiers in Psychiatry.

Copyright (c) 2012 Nielsen, Huang,

Hamon, Maili, Witkin, Fox, Cunningham and Moeller. This is an open-access article distributed under the terms of the Creative Commons Attribution Non Commercial License, which permits non-commercial use, distribution, and reproduction in other forums, provided the original authors and source are credited. 